\title{
APUNTES PARA RE-PENSAR LA RELACIÓN ENTRE LA CONFORMACIÓN RACISTA DEL ESTADO EN LATINOAMÉRICA Y LOS ESTUDIOS DE ESTRATIFICACIÓN Y MOVILIDAD SOCIAL EN ARGENTINA.
}

Jésica Lorena PLA ${ }^{1}$

\section{Resumen}

El artículo reflexiona sobre la necesidad de incorporar la articulación entre los conceptos de modernidad, Estado Nación y raza en el análisis de la estratificación y la movilidad social, en Latinoamérica en general y en Argentina en particular. Analiza el modo en qué el surgimiento y consolidación de los Estados Nación modernos ocurre conjuntamente a la consolidación de una división mundial del trabajo sustentada en criterios raciales y la manera en que esa división se cristaliza en una estructura social: el proceso de "racialización" de clases.

Palabras claves: Estratificación - movilidad social - Estado Nación - racialización invisibilización

\begin{abstract}
The article the need to incorporate the joint between the concepts of modernity, nation state and race in the analysis of stratification and social mobility in Latin America in general and Argentina in particular. It analyzes how the emergence and consolidation of modern nation-states occurs in conjunction with the consolidation of a global division of labor supported by racial and how that division is crystallized in a social structure: the process of "racialization" of classes.
\end{abstract}

Key words: Social Stratification - social mobility - Nation State - racialization- Invisibility

\section{Résumé}

Ce document se penche sur la nécessité d'intégrer l'articulation entre les concepts de la modernité, Etat-nation et de race dans l'analyse de la stratification et la mobilité sociale en Amérique latine en général et de l'Argentine en particulier. Analyser comment l'émergence et la consolidation des États-nations modernes se produit en conjonction avec la consolidation d'une division mondiale du travail soutenu par la race et comment cette division est cristallisée dans une structure sociale: le processus de «racialisation» des classes.

Mots-clés: Stratification - mobilité sociale - État-nation - racialisation - invisible

\footnotetext{
${ }^{1}$ Becaria de Posgrado del Consejo Nacional de Investigaciones Científicos y Técnicas con sede en el Instituto de Investigaciones Gino Germani, Facultad de Ciencias Sociales, Universidad de Buenos Aires jesicapla@conicet.gov.ar jesicapla@gmail.com
}

Fecha de recepción del artículo: Febrero 2012

Fecha de evaluación: Mayo 2012 


\section{Introducción}

"la dialéctica de la negación del otro precede a la dialéctica de la exclusión. La negación no se interrumpe: se transmuta. En la historia de la región hay continuidad temporal entre la negación y la exclusión: los descendientes de los negros que fueron esclavos traídos de África, y de los indios que fueron sometidos por la conquista, son hoy, en su mayoría, pobres y marginados (aunque no sean los únicos pobres y marginados). El estigma no se interrumpe ni con las revoluciones de la independencia, ni con las empresas modernizadoras ni con el Estado de derecho" (Calderón, Hopenhaym y Ottone, 1996: 68).

La articulación entre los conceptos de modernidad, Estado Nación y raza ${ }^{2}$ ha sido ampliamente analizada en las ciencias sociales, en particular para dar cuenta de la manera en qué el surgimiento y consolidación de la modernidad se da a la par de la conformación de los estados nación en base a una división mundial del trabajo, sustentada en criterios raciales. El presente artículo realizará un recorrido teórico e histórico sobre dicha relación, con el objetivo de distinguir la importancia de incorporar estas dimensiones en los estudios sobre estratificación y movilidad social, en Latinoamérica en general, y en Argentina en particular.

La sociedad capitalista ha necesitado de la conformación de estados-nación modernos como un modo de dominación de relaciones de desigualdad respecto del control de recursos de producción y de las instituciones y mecanismos de autoridad (Quijano, 2000b). Es con la consolidación del Estado Nación y la sociedad de clases, que aparece la idea de ciudadanía (Marshall, 1949), como un status o reconocimiento que determina la igualdad jurídica de las personas, independientemente de la posición social, desigual, que ocupen. La existencia de derechos y obligaciones que impone dicho reconocimiento jurídico establece una igualdad en un sistema estructuralmente desigual, un status simple sobre la cual elevar la estructura de desigualdad. Esta "igualdad ideal" lleva implícito la idea de que cada individuo tiene las mismas posibilidades de ocupar un espacio determinado en la estructura social. Este ideal guía el horizonte de expectativas y aspiraciones, haciendo que la desigualdad del sistema de clases "se vuelve aceptable" (Marshall, 1949). No obstante, como manifiesta Todorov (1991: 121) ese ideal de aspiraciones de igualdad encuentra sus límites, en particular en las diferencias físicas, como la "raza" límites que generan una estratificación propia que en la mayoría de los Estados modernos se superponen históricamente a una estratificación social real. Así, si el ideal de ciudadanía tiene sus orígenes en el conflicto de clases, el mismo está en construcción permanente, en términos de la expansión de la pauta de derechos y deberes o con relación a los grupos sociales que son incluidos o excluidos (Fleury, 1998). Se pone en evidencia la naturaleza discutible y frágil de la ciudadanía moderna (Giddens, 1982b en Crompton, 1994), dando cuenta de que la estratificación social no responde a un ordenamiento azaroso de individuos, sino que tiene basamentos estructurales de más larga data.

Bajo este marco, la ciudadanía es un espacio de conflictos y relaciones de fuerza, teñida de sentidos de dominación, como lo ha sido el criterio racial. Por este motivo, en las ciencias sociales se ha acuñado el concepto de etnicidad. La diferencia entre ambos conceptos y las bifurcaciones y sentidos que a lo largo de la historia ha tenido el segundo de estos, no es objeto

\footnotetext{
${ }^{2}$ Aquí se utiliza el concepto de raza, aludiendo a cómo este se construyó históricamente y cómo fue utilizado en pos de mecanismos de dominación. Como plantea Quijano (2003) la idea de raza es un invento, ya que no tiene ninguna relación con la estructura biológica de la raza humana ni existe asociación probada entre los rasgos fenotípicos y los procesos biológicos del organismo, tales como aquellos en los cuales están implicados los subsistemas neurológicos y mentales y sus funciones. Más adelante, se vuelve sintéticamente sobre este tema, para referir a la diferencia entre el concepto de raza y etnicidad, y la relación de estos con el conflicto permanente que subyace a la idea de ciudadanía.
} 
de este trabajo, pero si rescatar la idea de que mientras la raza fue utilizada como un concepto que dividía a la población humana bajo criterios biológicos, vinculados especialmente a atribuciones relativas a genotipos y fenotipos, etnicidad refiere a un concepto pos racial fuertemente influenciado por el constructivismo y el relativismo cultural: se concibe tanto la raza como los factores étnicos como construcciones sociales y culturales (Bello y Rangel, 2000). Los mismos autores recuperan de Giddens (1991) el concepto de etnicidad en tanto prácticas y perspectivas culturales que distinguen a una comunidad dada de personas, quienes se ven a sí mismos como diferentes de otros agrupamientos en una sociedad, y son percibidos por los demás de igual manera. Las características que pueden servir para distinguir unos grupos étnicos de otros son diversas, entre las que se destacan la lengua, la historia o la ascendencia (real o imaginada), la religión, etc. Sin embargo cabe aclarar, junto a Martínez Arias (2009:27) que el concepto de etnicidad a pesar de reconocer el lugar de la historia, el lenguaje y la cultura en la construcción de la subjetividad y de la identidad, surgió y mantuvo una connotación excluyente, discriminatoria e incluso inferiorizante durante mucho tiempo, ya que eran "los otros" los que definían estos rasgos, como se verá a lo largo del trabajo. Para el autor fue Hall quien se reapropió del concepto, al señalar

\begin{abstract}
...el hecho de que las identidades se habían liberado de sus anclajes en las clásicas historias lineales de la raza y la nación y que estaban redefiniendo su diferencia hasta el punto de poner en cuestión los modelos orgánicos y unitarios de la cultura y la identidad cultural. La noción de «nuevas etnicidades» se refiere, por tanto, a las múltiples formas de tráfico cultural generado por los procesos de globalización, así como a la convergencia de geografías transnacionales y transculturales de identificación a través de la apertura de nuevas redes diaspóricas de comunicación28, entendiendo a los grupos étnicos de un modo mucho más plural y matizado, como portadores y creadores de identidades múltiples y transversales (...)La identidad se transforma constantemente y nunca llega al final de la trayectoria. Esto no significa, sin embargo, que la identidad se construya en un vacío político y cultural. Apuntar a la elasticidad de la identidad, a su dinamismo, no implica que los horizontes sean ilimitados o que el pasado no tenga un peso considerable (Martínez Arias, 2009:29).
\end{abstract}

La etnicidad es entonces una construcción simbólica de grupos que puede dar lugar a relaciones complejas y contradictorias, cuyas fronteras se mantienen y manipulan no por los mitos de la raza biológica sino por la selección de realidades y mitos ligados a factores sociales, culturales, políticos y económicos (Smith Belote y Belote, 2000) ${ }^{3}$.

\footnotetext{
${ }^{3}$ Como se mencionó anteriormente, no es objeto de este trabajo realizar una definición exhaustiva del concepto de etnicidad, pues excedería los límites de este trabajo. Como menciona Restrepo (2004), parece haberse consolidado una lectura de la etnicidad que posee cuatro premisas centrales:(a) su contingencia, positividad y especificidad histórica; (b) su irreductibilidad o epifenomenalidad con respecto a otros entramados o precipitados de la vida social; (c) su inmanente heterogeneidad y polifonía en la filigrana de las prácticas e imaginarios de los disímiles actores sociales; y (d) su intrínseca relacionalidad y estrecha imbricación con articulaciones de poder y resistencia. Sin embargo, más allá de un aparente consenso general sobre esas cuatro premisas fundamentales, las diferencias sustantivas entre los diversos enfoques conceptuales no se han desvanecido ni resultan irrelevantes, por lo cual requieren un examen exhaustivo, que se puede consultar en su propio texto, así como en Bello y Rangel (2000), entre otros.
} 
Frente a estas cuestiones, cabe preguntarse entonces sobre cuál es el lugar que tiene la división racial del trabajo y la conformación de diferentes etnicidades en el proceso de estratificación ${ }^{4}$, es decir cuánto de esa diferencia física, visible en los cuerpos, influye en las posibilidades de movilidad social ${ }^{5}$. Es en respuesta a esta pregunta que en este artículo se propone un análisis de las características históricas de conformación del Estado en Latinoamérica en general y de Argentina en particular, considerando este tipo de análisis permitirá dar cuenta de procesos de discriminación, estigma y exclusión hacia la parte más pobre de la población, la población de origen mestizo (Margulis, 2002). Estas indagaciones son de particular importancia en todo el continente, pero adquieren una relevancia y dimensión particular en Argentina, donde la existencia de divisiones raciales y la conformación de etnicidades ha sido históricamente invisibilizada (Margulis, 2007).

El devenir de un país en conjunción dialéctica con su inserción en el sistema mundo (Wallerstein, 1974; Frank, 1969; Machuca, 2008; Gaitán, 2008) determina la estructura social del mismo. La misma a la vez que demarca patrones de movilidad social cristaliza formas de desigualdad (Kerbo, 2004). Así, consideramos vital repensar los estudios de estratificación social y movilidad en contextos de crecimiento y expansión económica, como los que caracteriza a Argentina desde el periodo 2003 (CENDA, 2005). Cabe mencionar que expansión económica no necesariamente implica desarrollo económico: la primera refiere a un crecimiento prolongado del Producto Bruto Nacional per cápita pero no necesariamente a un proceso de crecimiento auto-sostenido (Germani, 1969). Pero, por otro lado, la noción de desarrollo económico quizás no sea la más acertada como marco epistémico dentro del cual pensar las problemáticas de estratificación y movilidad social que queremos analizar en este artículo.

El concepto de desarrollo económico se impuso con fuerza en la posguerra, y es un reflejo y expresión de la reconfiguración del poder capitalista mundial, en base a un patrón euro céntrico de conocimiento que, desde el siglo XVIII, se configuró como uno de los instrumentos principales del patrón mundial de poder capitalista (Quijano, 2000b)- Ese patrón de conocimiento demostró ser un aparato extremadamente eficaz para constituir una explicación sobre Latinoamérica y sobre las posibles intervenciones sobre el continente (Escobar, 1999: 42). El supuesto hegemónico sobre el que descansaba dicho patrón de conocimiento era que el desarrollo refería de manera universal a un camino de crecimiento, razón por la cual era necesario identificar en cada país o en cada región los obstáculos al mismo y las formas de vencerlos (Quijano; 2000b). En Latinoamérica existieron dos vertientes que se enmarcaron en esta línea: la teoría de la modernización, asociada al estructural-funcionalismo, que dividió a la humanidad en áreas y le otorgó a la cultura la condición de sede y fuente de las explicaciones acerca de las diferencias entre los grupos humanos respecto del desarrollo, por lo cual era

\footnotetext{
${ }^{4}$ Cabe mencionar el trabajo reciente de Kaminker (2011) donde realiza un esfuerzo que se relaciona con los objetivos de este artículo, analizando la "in-visibilización” que la división racial ha tenido en el ámbito académico argentino en general, y en su articulo en particular en el análisis de la segregación residencial urbana.

${ }^{5} \mathrm{Si}$ bien no es objeto de este artículo, el concepto de movilidad social ha sido desdeñado por muchos teóricos por considerar que implícitamente refiere a una visión política según la cual los individuos tienen oportunidades de moverse hacia otras clases sociales, y lo harán de manera meritocrática según el esfuerzo que pongan en hacerlo, es decir, ese ideal de ascenso y expectativas basadas en el propio esfuerzo. Esta visión hegemonizó el estudio de la movilidad social durante décadas, de la mano del estructural funcionalismo, particularmente el norteamericano, e incluso sigue muy presente hoy en día en los estudios de los países del denominado primer mundo.

Sin embargo, creemos necesario retomar la preocupación del análisis de los procesos de movilidad social a la luz de los análisis de estratificación social, y principalmente centrándose en el concepto de clase, ya que el estudio de las pautas de estratificación y de desigualdad social se enriquece al incorporar la referencia a los procesos dinámicos que se producen entre las distintas posiciones que los sujetos pueden ocupar a lo largo de su vida, en relación a su situación de origen, y la percepción que ellos tienen sobre la misma, es decir, en relación a los procesos de movilidad social.
} 
necesario seguir las pautas culturales de los mismos. Esta visión abrió el camino a los análisis del paradigma de la modernización según el cual las sociedades seguirían un sendero de desarrollo que las llevaría al progreso (DESAL, 1965; Hoselitz, 1960).

Por su parte, la teoría del imperialismo capitalista, asociada, principalmente, al materialismo histórico $^{6}$, la cual atribuía al imperialismo capitalista y a la dependencia externa o a la dependencia estructural, la explicación de las diferencias entre desarrollados y subdesarrollados, atribuyendo al capitalismo caracteres inmanentes.

Pero existió otra visión, las llamadas "teorías de la dependencia"? (Borón, 2008), que surgen en la década de los sesenta construyendo una crítica a las teorías anteriormente mencionadas. Los teóricos de esta escuela "invirtieron" los términos de comprensión de los problemas de Latinoamérica: el continente era atrasado y subdesarrollado no por la ausencia de estructuras capitalistas, sino precisamente por la presencia las mismas, y particularmente por la forma en que se había insertado en un sistema mundo (Borón, 2008). Desde su "nacimiento" Latinoamérica fue incorporada al sistema capitalista, desintegrando patrones previos de poder y redefiniendo aquellos elementos y fragmentos estructurales que le fueran útiles o necesarios. Acorde a esta perspectiva, ni el capital, ni el capitalismo, como componentes del patrón mundial de poder, pueden ser entendidos por separado, así como tampoco la ubicación particular de los países, regiones, o espacios-tiempo, en la historia del capitalismo mundial (Quijano, 2000b).

Pero existe una dimensión adicional, inseparable de lo mencionado anteriormente en lo que a la conformación del Estado y la consolidación del capitalismo se refiere: el patrón de dominación mundial que emerge de dicho proceso se sustenta en la idea de raza en tanto estructura biológica que diferencia a la población humana entre inferiores y superiores, clasificación que no quedó en la enunciación de una mera descripción sino que se asoció y articuló con el control del trabajo, de la autoridad y de la subjetividad, generando efectos específicos sobre la estratificación social y las posibilidades de movilidad.

Fue el periodo colonial el escenario y el marco que permitió la constitución de la idea de raza como el instrumento universal de clasificación social básica de toda la población del planeta, constituyendo un patrón mundial de poder capitalista caracterizado por una dualidad "colonial/moderno" (Quijano, 2000b: 82).

Se genera así una dependencia histórico estructural, por la cual el patrón de inserción en el sistema mundo refiere no sólo a la división social o económica del trabajo, al control del excedente y los mecanismos de autoridad, sino también a una división racial del mismo (Quijano, 2000a, 2000b, 2005), en una disputa de poder donde un grupo se impuso como

\footnotetext{
${ }^{6}$ Marini (1991) realizó una crítica específica de los análisis de los investigadores marxistas ortodoxos, por estudiar ciertos procesos desde una formalización que rompe la relación entre lo concreto y lo abstracto (las descripciones empíricas corren paralelamente al desarrollo teórico pero sin fundarse en él) y a la vez que ante dicha dificultad recurren a otras categorías cayendo en una falta de rigor conceptual y metodológico.

${ }^{7}$ Por no ser objeto de este trabajo, no se ahonda en las características ni especificidades de esta teoría, pero cabe recalcar que al interior de la misma existieron diferentes corrientes, por lo cual sería un error tratarlas como un todo homogéneo (Beigel, 2006). A modo de síntesis, cabe recuperar la división hecha por Torre Novoa, 1979). En primer lugar, la "teoría de la dependencia" que se presenta a sí misma como alternativa teórica con relativa autonomía, en las figuras de Vania Bambirra y Theotonio Dos Santos. Por otro lado, tenemos la corriente que se inscribe a sí misma dentro del materialismo dialéctico, buscando en su interior un "espacio" para introducir el concepto de dependencia: Cardozo y Faletto, Francisco Weffort y su polémica con los anteriores autores, Aníbal Quijano, Rui Mauro Marini y Tomás S. Vasconi. En tercer lugar se encuentra la corriente que a pesar de utilizar el término de "dependencia" queda inmersa en el pensamiento neoclásico; particularmente Oswaldo Sunkel, Celso Furtado y Aníbal Pinto. Finalmente, en cuarto lugar, se encuentra la tendencia que usa la noción de dependencia en un sentido ideológico, particularmente en gobernantes de la región. Cabe mencionar los aportes de Guunder Frank y Stavenhagen como precursores de esta teoría (Borón, 2008).
} 
legitimo, como veremos adelante no sólo basado en criterios biológicos sino haciendo un giro hacia los criterios culturales.

En esta interpretación entran en juego no sólo una confrontación con un tipo determinado de racionalidad económica sino también epistémico. A partir de estas bases Quijano cuestiona y alimenta al mismo tiempo los postulados básicos de la teoría de la dependencia mencionados anteriormente.

Así, el análisis de la conformación racial de las estructuras sociales latinoamericanas, es decir escenarios de dependencia histórico-estructural, debería aportar elementos fundamentales para los análisis de la estratificación y la movilidad social (Costa Pinto, 1952; Hammond, 1963; Nogueira, 2008; Costa Ribeiro, 2007) ${ }^{8}$.

Quintero (2010) analiza el modo en que Quijano postula que todas las formas de existencia social implican cinco ámbitos de existencia en correlación e interconexión: trabajo, sexo, subjetividad / inter-subjetividad, autoridad colectiva y naturaleza. Es la disputa por el control de estos ámbitos lo que conforman las relaciones de poder, en sus tres elementos: dominación, explotación y conflicto.

De esta manera, este artículo buscará profundizar conocimientos teóricos que ayuden a comprender que los procesos de estratificación social no deberían ser analizados $\mathrm{y}$ comprendidos sólo a partir del estudio de determinados factores materiales, sino a partir de una conformación que se ancla en el proceso de constitución de clases en América Latina y que sigue vigente hasta nuestros días, marcado por una característica racista, la cual al mismo tiempo es in-visibilizada por los sectores en disputa, y puesta en cuestión por los sectores que disputan el poder, en una conformación constante de fronteras étnicas, como señala Guerrero (2000).

Concebida así la estratificación social no debe ser pensada como una estructura rígida y / o estática sino como un proceso de constitución política y de reproducción social (Hammnond; 1963) en constante tensión con el concepto de ciudadanía.

En pos de cumplir el objetivo de este artículo, se presenta a continuación un primer apartado en el cual se examina históricamente la conformación de un sistema - mundo a nivel global, y del tipo y modo en que Latinoamérica se inserta en dicho sistema. Asimismo, se analiza como los patrones y criterios de legitimación de ese sistema mundo impactan en las características que asumen los estados latinoamericanos, en cuanto a su conformación política, económica y social. A la par de estas indagaciones se dejan expuestas las teorías que dieron origen y legitimaron dicha división mundial.

A continuación, un tercer apartado enuncia las características de la inserción de Argentina en el sistema - mundo, así como la manera en que el proceso de legitimación de la división racial del trabajo se hace presente en este país. Para hacerlo se repasan los principales pensadores del

\footnotetext{
${ }^{8}$ Los autores mencionados han realizado estudios en esta dirección. En particular, Costa Pinto (1952) realiza un análisis de los datos censales de Brasil entre 1870 y 1940. A partir de lo hallado, propone un marco de interpretación según el cual aún cuando Brasil atravesó un proceso de modernización que produjo un escenario en el cual las desigualdades de clase imperan por sobre las desigualdades raciales o de casta, el mismo proceso lleva a un incremento de la movilidad social que terminó redundando en un retorno de dichas desigualdades. El trabajo de Hammond (1963), demuestra la existencia de barreras de los sectores negros y pardos para alcanzar los puestos más favorecidos de la estructura social. Al hacerlo, contrasta estas evidencias empíricas con el sentido común que impera en Brasil acerca de la no existencia de prejuicio o discriminación racial. Para el autor, dicha imagen sirve como una forma de impedir el reconocimiento de un problema social de relevancia. Estudios más recientes confirman que las diferencias de oportunidades siguen existiendo, como ser los trabajos de Nogueira (2008), en San Pablo, o de Costa Ribeiro (2007) en todo Brasil. En el caso de Costa Ribeiro, encuentra una particularidad, que la desigualdad racial en las oportunidades de movilidad social tienen su origen en las clases sociales mejor ubicadas en la estructura social, es decir, que las elites blancas reproducen su posición.
} 
siglo XIX y la manera en que esas ideas tomaron cuerpo y se afianzaron en una estratificación social que llega a nuestros días.

Finalmente, se ofrece finalmente una reflexión sobre la importancia de incorporar esta dimensión de análisis a los estudios sobre la estratificación y la movilidad social en Argentina en particular, pero que puede ser extensible, considerando las peculiaridades de cada país, a toda Latinoamérica.

\section{Sobre la conformación histórica: Modernidad, Estado Nación y división racial}

Como se mencionó en el apartado anterior, la relación entre modernidad, Estado Nación y división racial, es una relación de particular interés para el análisis de la realidad social. Esa relación es una herencia del periodo colonial. La conquista y colonización de Latinoamérica "selló", en un mismo giro, la constitución de la modernidad y del capitalismo como un sistema mundial económico, bajo un patrón de poder mundial en el cual Europa occidental se constituye como el centro y la "raza blanca" (europea) como la biológica y culturalmente superior (Quijano, 2000b; 2003). Para llegar a este punto fue necesario la articulación de todas las formas históricas de control del trabajo existentes, supeditando e imponiendo su legalidad, bajo el nuevo patrón de dominación: la relación capital - trabajo (Cueva, 1977). Es durante este proceso de apropiación del producto de trabajo que Europa occidental deviene identidad hegemónica y sede central del comercio mundial. Se constituye así el punto de partida de la modernidad, dado que re-identifica a la población mundial en base a un "centro", que actúa como controlador de las formas de producción y de conocimiento (Quijano, 2003).

Ahora bien, para la supeditación de formas económicas y sociales anteriores al capitalismo en Latinoamérica, fue necesario la existencia y legitimación de mecanismos simbólicos y culturales que lo hicieran posible, ya que la realidad preexistente a la conquista descansaba sobre tiempos y espacios distintos a los que venían a imponer los españoles (Gruzinski, 2004). El contexto de la conquista, no sólo fue un contexto de guerra, sino también fue para los habitantes de los territorios de Latinoamérica un contexto de desorden, con pérdidas de referencias simbólicas, descomposición de jerarquías preestablecidas y la consecuente imposibilidad de representación social (Gruzinski; 2004; Todorov, 1987), un contexto de rupturas y cambios de identidades étnicas, que significó un corrimiento de las mismas.

El mundo colonial se va a constituir a partir de determinadas ideas de la diferencia entre un "otros" y un "nosotros". Durante toda la etapa colonial en Latinoamérica, los españoles pasaron de una visión que negaba la humanidad del indio a una visión paternalista. Este cambio se da a partir del descenso de la población (debido a diferentes cuestiones, como ser enfermedades, guerra), descenso que amenazó la rentabilidad de la colonia. La visión paternalista protegerá al nativo, pero lo hará en pos de una acentuación de la población mestiza, en su diferencia con la población blanca. Este proceso, enmarcado en el concepto de "resocialización", se da en un marco político ideológico determinado: las teorías evolucionistas que legitiman la existencia de las colonias y su explotación (Quijano, 2000b; 2005; Margulis y Belvedere, 1999).

Dichas teorías postulaban la existencia de un patrón biológico que determinaba la existencia de diferentes razas con diferentes jerarquías. El edificio cultural del imperialismo está basado en la noción de superioridad occidental, a partir del establecimiento de una jerarquía de razas y civilizaciones: la superior, blanca europea; la inferior, negra, mestiza, primitiva, salvaje (Saíd, 2005). A partir de estos, la identidad racial se constituye como una clasificación básica de la sociedad que asume un papel decisivo en la dominación de Europa sobre América Latina; las identidades raciales se asocian a jerarquías, lugares y roles sociales (Quijano, 2003).

En Europa, el señor feudal encarnaba, hasta cierto punto, la primitiva tradición patriarcal, de suerte que respecto a sus siervos se sentía naturalmente superior, pero no étnica ni nacionalmente diverso. Al propio terrateniente aristócrata de Europa le ha sido dable aceptar un nuevo 
concepto y una nueva práctica en sus relaciones con el trabajador de la tierra. En la América Colonial, mientras tanto, se ha opuesto a esta evolución la orgullosa y arraigada convicción del blanco, de la inferioridad de los hombres de color (...) en el latifundista costeño, han actuado a la vez los sentimientos del aristócrata medieval y del colonizador blanco, saturados de prejuicios de raza" (Mariategui, 1995: 67-58, las cursivas son nuestras).

Para Europa, para el hombre colonizador europeo, la superioridad que había alcanzado en la esfera militar y en la tecnológica se entendió como una misión: la de llevar al mundo entero su forma de vida, eliminando cualquier otro modo de producción social (Quijano, 2000b): "la obligación del hombre blanco" (Stavenhagen, 1994).

La comprensión del mundo se configura entonces a partir de una división temporal del mismo, entre los evolucionados (europeos) y los que debían evolucionar hacia esas formas de vida (Quijano, 2000a; 2000b; 2003; 2005), constituyendo un régimen de verdad que es la quintaesencia de la modernidad, profundizado y alentado por la economía y el desarrollo (Escobar, 1999: 40). Es el momento en que devienen centrales en las ciencias sociales categorías como evolución, progreso o desarrollo9, los cuales se traducen en la instauración de un modo de producción económico y una división mundial del trabajo que tiene sus fundamentos en las "ventajas comparativas". Esa idea determina la forma en que los diferentes pueblos deben explotar su economía a partir de ese momento: en el modo en que Europa indica (Preiswerk y Perrot, 1979).

El otro colonizado, racial y culturalmente inferior, debía aceptar los preceptos de Europa, configurarse como un "afuera" plausible de ser conocido por teorías e intervenidos desde el interior (Escobar, 1999) y, a la postre, legitimar la expansión colonial ${ }^{10}$.

Ahora bien, la occidentalización o legitimación de occidente en Latinoamérica se produjo a partir de un conjunto de medios que actuaron sobre los planos simbólicos, como ya fue mencionado, y materiales (Gruzinski, 2000; Preiswerk y Perrot, 1979). Se asiste así a un proceso de deculturación, de desarraigo de la cultura nativa con fines de explotación económica, ya sea para la exportación de las riquezas naturales como para la "creación" de mano de obra (Moreno Fraginals, 1977). El mismo implicó la réplica del viejo mundo y sus instituciones, especialmente de la propiedad privada y la mercancía (Margulis, 2006). La modernidad instaura así la idea del intercambio como algo natural, anulando el proceso histórico que lo conforma y las diferencias cualitativas entre diversos trabajos humanos, bajo una sola diferencia, el dinero (Gruzinski, 2000; Margulis, 2006). Estos mecanismos sirven como herramienta de hegemonía para la clase dominante que se refugia en su cultura e identidad para lograr su supervivencia (Moreno Fraginals, 1977) y extender su dominio colonial, inclusive hasta la actualidad (Quijano, 2003).

En síntesis, el sistema capitalista se constituye como articulador de todas las relaciones capital / trabajo, en función de un tipo determinado de sistema mundo. Paralelamente se constituye el entrelazamiento raza / trabajo, conformando el punto central de partida de la modernidad: la raza distribuye y clasifica a la población mundial en términos de las nuevas estructuras de

\footnotetext{
${ }^{9}$ Ya se mencionó en la introducción el contenido simbólico de este concepto. Cabe destacar que según Ivan Illich (en Escobar, 1999: 39), el concepto de desarrollo atravesó a lo largo de la historia por seis etapas de metamorfosis, siempre basado en la percepción del extranjero como alguien que necesita ayuda: el bárbaro, el pagano, el infiel, el salvaje, el nativo y el subdesarrollado. Si bien puede pensarse que el concepto de subdesarrollado se pude tomar, en base a su óptica de posibilidad de igualdad a través del desarrollo, como respuestas a las concepciones más racistas como "primitivo" y "salvaje", no ha sido capaz de corregir sus connotaciones negativas.

${ }^{10}$ Ya se mencionó anteriormente que Martínez Arias (2009) analiza en este contexto el surgimiento del concepto de etnia / etnicidades, como una clasificación que reconocía los componentes culturales, pero "definidos" por los "otros" y nunca por el mismo grupo que así se clasifica
} 
poder, deviniendo instrumento de clasificación básica de la sociedad. El color de la piel se constituye como modo de dominación mundial (Quijano, 2000a).

Los procesos mencionados se anclan en el proceso de conformación de clases sociales en Latinoamérica. La división cultural del trabajo prepara así el terreno para la racialización de las relaciones sociales y económicas (Stavenhagen, 1994). La racialización de las relaciones de clase (Margulis, 2006), refleja la superposición de significados y entramados que conforman las desigualdades sociales basadas en el color de la piel, determinando una prolongación de las categorías coloniales que se consolidaron en el siglo XIX (colonialidad del poder, en términos de Quijano, 2003).

El proceso de producción social del "color" como el signo principal de una clasificación social universal del mundo colonial/moderno y euro centrado del capitalismo no fue, sin duda, inevitable. Si fue su establecimiento desde el siglo XVI hasta la actualidad lo que dio origen, explicación y sentido a la imposición de la categoría "raza" y del "color" como su marca externa, (Quijano, 2000a; 2000b), imponiendo así una tecnología de dominación / explotación que hasta nuestros días sigue vigente (Margulis y Belvedere, 1999).

El Estado nación contemporáneo no ha sido capaz de romper con el pasado y enfrentar las realidades coloniales. Cuando los mercados de trabajo se segmentan y polarizan, la concentración tecnológica y de capital crea oportunidades para los sectores altamente calificados pero "desecha" a los "no competitivos", la economía informal pasa a ser un "colchón" de los sobrevivientes de un embudo, a través del cual los inmigrantes de zonas rurales pobres o países subdesarrollados o antiguas colonias son canalizados hacia mercados específicos caracterizados por los bajos sueldos y la baja productividad (Salvia y Chávez Molina, 2007). Que esa diferenciación socioeconómica sea también racial y cultural no es un mero accidente (Stavenhagen, 1994).

\section{Las características del proceso de racialización de clases en Argentina}

Como se mencionó en el apartado anterior, en Latinoamérica la conformación de los Estado Nación se dio a la par del proceso de consolidación del sistema mundial capitalista, la división mundial del trabajo y la división racial al interior de los mismos.

Ahora bien, las características de dicho proceso adquieren ciertas especificidades en el territorio del Río de la Plata, debido a la particularidad del proceso histórico. En este territorio, desde la época de su constitución, la población era minoritariamente blanca, existiendo una mayoría mestiza e india. Los mestizos, se caracterizaban por ser una especie de población "desclasada" o intermedia, entre la vida urbana, blanca, y la rural, india. Los indígenas, a diferencia de los grandes grupos hallados en países como México, se caracterizaban por ser una población dispersa, nómade, de cazadores o recolectores. Junto a estas características, fue de importancia la introducción del caballo por el hombre blanco en la primer fundación de Buenos Aires, ya que eso le permitió al indígena un dominio de amplios territorios, y consecuentemente de la tierra, lo cual redunda en que la lucha por esta se convierte en la principal manera de relación entre el indígena y el hombre blanco.

Si bien el territorio del Río de la Plata con la revolución de 1810 presentó un espíritu de cambio con respecto a la población aborigen, las leyes entonces proclamadas (igualdad jurídica, derogación de la mita), alcanzaron en su momento sólo a la población mestiza urbana, y no a los tehuelches, araucanos o carhuaz, que mantenían una relación de hostilidad con el Estado en formación. Será contra esas poblaciones que se llevará una lucha de exterminio en la segunda mitad del siglo XIX.

La llamada generación del 37, así como luego la generación del 80, fueron los representantes de una doctrina político social de la época que les era funcional, dado que activaba la expansión de Europa en el continente Latinoamericano, no sólo a nivel material sino también simbólico.

Entre las características fundamentales de dichas generaciones es posible mencionar el hecho de que sus pensamientos sociales y políticos encontraban fundamento en las ideas positivistas, 
biologicistas y etnocentristas del racismo científico que hegemonizó el pensamiento europeo durante el siglo XIX, reflejados en las figuras de Ernst Renan, Joseph Arthur de Gobineau, Gustav Lebon, Hippolyte Taine y Houston Stewart Chamberlain. Si bien no nos adentraremos en las especificidades de dichas figuras ni de su pensamiento, cabe mencionar que todos ellos compartían una serie de preceptos fundamentales que eran los que impregnaron a las mencionadas generaciones (Todorov, 1991; Margulis y Belvedere, 1999). Dichas características podrían sintetizarse en estos seis puntos: a) Las razas existen y se trata de agrupamientos humanos con características físicas comunes, cuyas características son consideradas hereditarias y transmisibles por sangre; b) Existe una continuidad entre lo físico y lo moral: el hombre blanco era superior racial y culturalmente, dado que traía en forma inherente los valores y conductas propios del capitalismo; c) El individuo actúa según el grupo racial al que pertenece, es decir que existe una superioridad del grupo por sobre la acción individual; d) Las razas no sólo son distintas, sino que hay superiores e inferiores. La raza blanca es la innatamente superior; e) Las razas inferiores no pueden transformarse por medio de la educación; f) Esta concepción de la humanidad no sólo deviene en una propuesta teórica o cultural, sino que lleva implícito un ideal político.

Consideremos además que en el territorio de lo que es hoy la Argentina, durante el periodo de las guerras de la Independencia, el enfrentamiento de las fracciones unitarias con Rosas exasperó el sentimiento anti - negro en una amplia proporción de la población porteña. Rosas dirigió especial atención a los afro-argentinos, sustentándose en una concepción que consideraba importante la relación con las masas (Reid Andrews, 1989). Dicha concepción se transmutó en la incorporación de una gran cantidad de población negra entre sus filas y el otorgamiento de concesiones sociales. El racismo de los unitarios blancos se combinó con su odio por Rosas y los federales en la conformación del "negro" como símbolo recurrente del salvajismo y barbarie, características asociadas a la figura misma de Rosas.

Estas concepciones impregnaron los proyectos políticos de constitución del moderno Estado nación argentino.

Por un lado, Domingo Faustino Sarmiento consideraba que "la instrucción sola no sería suficiente para sacar a la Argentina de su barbarie; se requería real infusión de genes blancos" (Margulis y Belvedere, 1999). No obstante, creía en la posibilidad de una propuesta civilizatoria, de allí el nombre de racismo civilizatorio que se le da a su doctrina, propuesta que sacará a la barbarie de su ociosidad, rebeldía, salvajismos y brutalidad.

Las palabras de Juan Bautista Alberdi, reflejan el mismo tono de época:

haced pasad el roto, el gaucho, el cholo, unidad elemental de nuestras masas populares, por todas las transformaciones del mejor sistema de instrucción; en cien años no haréis de él un obrero inglés que trabaja, consume, vive digna y confortablemente" (en Margulis y Belvedere, 1999).

Para Alberdi era posible el mejoramiento de la raza humana, a través de la mezcla de diferentes tipos de ésta. Implantar en el país el origen europeo, permitiría, la construcción de un nosotros civilizado, urbano, católico y republicano. Este proceso se daría por una depuración de la raza, ya que Alberdi creía que el gen blanco tendería a predominar por sobre otros.

José Ingenieros, en cambio, tenía una concepción evolucionista (racismo evolucionista), según la cual la conformación de la sociedad argentina se daría por una lucha de razas, en la cual tendería a prevalecer la europea, de la cual el país era hijo, y no la América mestiza a la cual nada se le debía. La lucha de razas llevaría al triunfo de la raza superior y a la eliminación de la raza inferior, la mestiza. Se aleja así de las concepciones de Alberdi, ya que para él 
El resultado inevitable de mezclar razas inferiores con otras superiores era una descendencia raquítica, simiesca, con todo los defectos de la raza acentuados por la raza villana" (en Margulis y Belvedere, 1999).

Más allá de las diferencias específicas entre los autores, en las que no ahondaremos por no ser objeto de este trabajo, lo que interesa rescatar es como en todas las interpretaciones existe un pasaje de lo racial a lo cultural. Ese pasaje es posible debido a la fe inquebrantable de los unitarios, en ese entonces en el poder, en la innata superioridad de las republicas europeas (Margulis y Belvedere, 1999), su cultura, sus formas sociales, su economía.

El proyecto político de la generación del ochenta, impregnado de las concepciones señaladas, será el de incorporar a la vida argentina a un sujeto racial determinado, por medio del incentivo a la migración de población europea. Al asimilar a dicha población a una raza idealizada y culturalmente superior, el mismo proyecto excluye al aborigen. El proyecto de poblar el "desierto" argentino (territorio dominado por el aborigen y su caballo, como se mencionó anteriormente) por medio de la inmigración masiva europea, es un proyecto excluyente, que idealiza a un sujeto, el europeo, pero también a su cultura, su industria, su ciencia, excluyendo, en el mismo giro, no sólo al aborigen sino también a su cultura.

Ahora bien, el proyecto nacional de la ya mencionada generación de 1880, teñido de estas concepciones, no es sólo un proyecto político y simbólico, sino que es un proyecto económico que busca insertar al Estado Argentino en la división internacional del trabajo. Volvemos así al apartado anterior, en el sentido que se asocia el concepto de raza a un ideario cultural y a una serie de instituciones propias del mundo europeo: el librecambio, la propiedad privada y su síntesis: la mercancía. De esta manera, la incorporación de una determinada población implicaba también favorecer la inversión de capitales extranjeros, ya que dicha incorporación se traducía en la exportación de las leyes y culturas con el objetivo no sólo de poblar el país sino también de exportar sus leyes y cultura.

En síntesis, la conformación del Estado nación argentino se da a partir de una homogeneización (Clastres, 1987) que se basa en una estructura del conocimiento sobre el "yo" y el "otro" (Saíd, 2005) que tiene fundamento en una idea propia del "nosotros / europeo" basada en la negación del "otro / indio / mestizo". Establece así clasificaciones sociales jerárquicas que inscriben en sí mismas modelos culturales basados en el color de la piel, tal como se vio en el apartado anterior. El Estado Nación se asocia a una noción de cultura homogénea única y representativa del pueblo, tanto en identidad como en historia (Stavenhagen, 1994).

La constitución de la identidad nacional argentina se da a partir de una europeización de la población, de la cultura y sus instituciones. La identidad nacional desempeña una doble función: por un lado fortalece a la comunidad al interior, con respecto a sus relaciones con el exterior. Pero por otro lado consolida el Estado internamente, es decir, consolida la autoridad de los grupos en el poder por sobre el resto de la población (Stavenhagen, 1994). Este proceso de racialización de las relaciones de clase se refleja en el proceso de invisibilización de la población negra a nivel de la estadística oficial ${ }^{11}$.

A partir de la segunda mitad del siglo XX, el proceso de racialización de clases asume un nuevo matiz. Ante las grandes migraciones internas hacia la gran ciudad, y lo que significó la llegada del peronismo al poder, reaparece el "otro" en este caso, el "cabecita negra". Si el inmigrante europeo aportaba futuro y progreso al país, el migrante interno reaviva la historia de descalificación del otro, ocioso, salvaje, bárbaro, y lo hace portador de la historia de exclusión del mestizo de Occidente (Margulis, 1999).

Las tendencias descalificadoras y racialistas que se abrieron en esos procesos históricos, se observan en la actualidad en categorizaciones simbólicas que perduran (términos como el

\footnotetext{
${ }^{11}$ Ya hacia fines del Siglo XIX se observaban publicaciones que hacían gala del "blanqueamiento" de Buenos Aires. Un ejemplo de esto es que el resumen del censo de 1895 incluía un anuncio de que los negros habían desaparecido del país (Margulis y Belvedere: 1999)
} 
ocioso, el salvaje, el bruto; el villero, el cabeza, el bolita), dirigidas a aquella población que posee en su cuerpo los caracteres del mestizaje. Esta negación se transmuta a lo largo de la historia del Estado nación argentino (Margulis y Belvedere, 1999), adquiriendo diferentes matices, que definen las tensiones y negociaciones que subyacen al concepto de ciudadanía. Guerrero (2000) señala como en la actualidad surgen en Latinoamérica movimientos "étnicos" que irrumpen en el espacio público y redefinen las escenas políticas nacionales en un giro paradójico: cuando la republica democrática parece afianzarse, pretendiendo afianzar la idea de igualdad, y cuando el "sentido común" las había dado por desaparecidas o en el mejor de los casos como un pueblo "testigo" de un pasado que ya no existía.

\section{Comentarios finales: estratificación, movilidad, y el estigma del mestizaje}

El proceso de racialización de las relaciones de clase tiene su origen en la conformación del sistema mundo característico de la modernidad, la división mundial del trabajo que ese proceso genera, pero también la división racial entre Estados y al interior de los mismos. Genera un efecto sobre los sistemas de estratificación, así como determinadas barreras para la movilidad social de los sectores que llevan en su cuerpo las marcas del mestizaje, la herencia del mundo colonial. En este proceso, la disputa por el poder también implica una disputa de sentidos y la conformación de nuevas etnicidades, que irrumpen en la escena política y actúan sobre el mismo.

En Argentina este proceso tiene una particularidad: comienza en el siglo XIX con la conformación del Estado Nación, la lucha contra "el indio", y se revitaliza con los procesos de migración del campo a la ciudad que se dan a partir de la posguerra, en un contexto de advenimiento del peronismo como doctrina política y de la industrialización como modelo económico.

No obstante el avance en materia de derechos sociales y de oportunidades de ascenso social para diversos sectores de la población, como diversas investigaciones demuestran (Kessler y Espinoza, 2007), la discriminación y exclusión hacia los sectores sociales que llevan en su piel las marcas del mestizaje, sigue vigente (Margulis, 1999).

La revisión de bibliografía sobre los procesos de conformación de los modernos Estado nación latinoamericanos y su relación con la hegemonía de un proyecto político basado en concepciones racialistas, aportó información que contextualiza el problema planteado en un proceso histórico de larga duración.

Habiendo desarrollado una revisión histórica, dentro de un marco teórico y epistémico específico, de ese proceso de racialización, consideramos que es una dimensión que los estudios sobre estratificación y movilidad social deberían hacer un esfuerzo por incorporar, en pos de enriquecer su mirada.

La estratificación social entonces, no debe ser pensada como algo estático o como la mera distribución de personas en puestos de trabajo; tampoco debe pensarse la movilidad social inter -generacional como un proceso de "recambio" entre generaciones de quienes ocupan los lugares en la estructura social. Existe, en cambio, lo que la sociología ha sabido llamar proceso de reproducción social y relaciones de poder, cambiantes e históricas. Si la literatura revisada manifiesta que las diferencias basadas en los caracteres fenotípicos de aquellos que llevan en su cuerpo las marcas del mestizaje ha permanecido vigente en la historia argentina a lo largo de todo el siglo XX, cabría preguntarse si la misma se mantiene vigente, si los grupos étnicos han generado resistencias, oposiciones, en pos de expandir la pauta de derechos, y de qué manera afectan estos procesos las irrupciones de movimientos políticos basados en etnicidades en otros países de Latinoamérica.

Si en la actualidad las formas discriminatorias asumen formas culturales, ante la pérdida de vigencia de la justificación científica, estudiar estos fenómenos asume vital importancia porque permite visibilizar procesos que aparecen silenciados, aportando elementos que pueden influir 
Papeles de Trabajo No 23 -Julio 2012 - ISSN 1852-4508

Centro de Estudios Interdisciplinarios en Etnolingüistica y Antropología Socio-Cultural

en la discusión académica pero también política. En palabras de Saíd (2005: 53), la única vía de la cultura para no cargar con el pasado es enfrentarlo en toda su complejidad, con el objetivo de seguir constituyendo con audacia, inteligencia e innovación.

\section{Referencias bibliográficas}

BAMBIRRA, VANIA (1990) "El Estado en Brasil: del dominio oligárquico a la apertura controlada", en GONZÁLEZ CASANOVA (coordinador) (1998) El Estado en América Latina. Teoría y práctica. Siglo XXI - Universidad de las Naciones Unidas. México. pp. 247-266.

BEIGEL, FERNANDA (2006) "Vida, muerte y resurrección de las "teorías de la dependencia" en AAVV (2006) Crítica y teoría en el pensamiento social latinoamericano. CLACSO. Buenos Aires. pp. 287-326.

BELLO, ALVARO Y MARTA RANGEL (2000) "Etnicidad, 'raza' y equidad en América Latina y El Caribe", Documentos de la CEPAL Fuente: http://www.eclac.cl/publicaciones/xml/4/6714/Lcr 1967 rev.21.pdf (Consultado el 10-042012).

BORÓN, ATILIO A. (2008) “Teoría(s) de la dependencia”, en Realidad Económica No 238, 16 Agosto/30 Septiembre 2008. pp. 20-43.

CALDERÓN, FERNANDO; MARTÍN HOPENHAYM Y ERNESTO OTTONE (1996) Esa esquiva modernidad. Desarrollo, ciudadanía y cultura en América Latina y el Caribe. UNESCO Nueva Sociedad. Caracas.

CARDOSO, FERNANDO ENRIQUE, FALETTO, ENZO (1969). "Desarrollo y dependencia", en MARINI, RUY MAURO Y THEOTONIO DOS SANTOS (coordinadores) (1999) El pensamiento social Latinoamericano en el siglo XX. UNESCO. Caracas.

CENDA (2005), “¿La vuelta de la industrialización sustitutiva?”, en El trabajo en Argentina. Condiciones y perspectivas. Informe trimestral. Centro de Estudios para el Desarrollo Argentino. Buenos Aires.

CLASTRES, PIERRE (1987) "Sobre el etnocidio" en Investigaciones en Antropología Política. GEDISA. México.

COSTA PINTO, LUIS (1952), O Negro no Rio de Janeiro: Relações de Raça numa Sociedade em Mudança. Companhia Editora Nacional. São Paulo.

COSTA RIBEIRO, CARLOS ANTONIO (2007) "Class, race, and social mobility in Brazil”, en Dados, Vol. 3, Rio de Janeiro.

CROMPTON, ROSEMARY (1994) Clase y estratificación, una introducción a los debates actúales. Madrid. Editorial Tecnos.

CUEVA, AGUSTÍN (1977) "El desarrollo oligárquico dependiente del capitalismo" en CUEVA AGUSTÍN El desarrollo del capitalismo en América Latina. Siglo XXI Editores. México.

DESAL (1965) América Latina y desarrollo social, HERDER, Barcelona.

DONZELOT, JACQUES (2007) La invención de los social. Ensayo sobre la declinación de las pasiones políticas. Nueva Visión. Buenos Aires.

DOS SANTOS, THEOTONIO (1974) "La estructura de la dependencia", en Realidad nacional latinoamericana. Lima: Edit. Instituto Nacional de Investigación y desarrollo de la Educación, Ministerio de Educación, 1974, pp. 127- 150.

ESCOBAR, ARTURO (1999) El final del salvaje. Naturaleza, cultura y politica en la antropología contemporánea. CEREC. Bogotá. pp. 33-99.

FLEURY, SONIA (1998) "Politicas sociales y ciudadanía”. BID INDES. Washington.

FRANK, GUNDER (1969) Capitalism and underdevelopment in Latin America. Monthly Review Press. New York and London.

FURTADO, CELSO (1966) "Factores estructurales del estancamiento latinoamericano", en MARINI, RUY MAURO Y DOS SANTOS, THEOTONIO (coordinadores) (1999) El pensamiento social latinoamericano en el siglo XX. UNESCO. Caracas. 
GAITÁN, ALFREDO (2008) "Los legados del desarrollo excluyente: desigualdad y pobreza en el capitalismo periférico sudamericano", Presentado en el seminario "producción de Pobreza en América Latina y El Caribe", Lima, Perú, 15 al 17 de Octubre de 2008, CLACSO CROP DESCO.

GERMANI, GINO (1969) "Las etapas del proceso de modernización en América Latina”, en Sociología de la modernización. Paidós. Buenos Aires.

GIDDENS, ANTHONY (2000) Sociología. Capítulo 9. Alianza Editorial, Madrid. Tercera edición revisada. pp. 277-315.

GONZÁLEZ CASANOVA, PABLO (1970) "Sociedad plural, colonialismo interno y desarrollo", en CARDOSO, FERNANDO H., PINTO, ANÍBAL, SUNKEL, OSVALDO (compiladores) (1970) América Latina, ensayos de interpretación sociológico-política. Editorial Universitaria, Colección Tiempo latinoamericano, Santiago de Chile. pp.164-183.

GRUZINSKI, SERGE (2000) El pensamiento mestizo. Paidós. Barcelona.

GRUZINSKI, SERGE (2004) La colonización de lo imaginario. Fondo de Cultura Económica FCE. México.

GUERRERO, ANDRES (2000) "El proceso de identificación: sentido común ciudadano, ventriloquia y transescritura" en Guerrero, Andres (compilador) Etnicidades, ILDIS FLACSO Fundacion Friedrich Ebert, Ecuador.

HAMMOND, HARLEY ROSS (1963) "Race, Social Mobility and Politics in Brazil" en RR Race and Class, Vol. 4, No. 2, 3-13.

HOSELITZ, BERT (1960). Sociological Factors in Economic Development. The Free Press. Glencoe.

KAMINKER, Sergio Andrés (2011) "La dimensión racial en el análisis de la segregación residencial urbana en Puerto Madryn, Chubut", en Papeles de Trabajo, Centro de Estudios Interdisciplinarios, Etnolingüísticas, Antropológicos y Socioculturales, Rosario, n. 22, dic. 2011. Disponible en http://www.scielo.org.ar/scielo.php?script=sci_arttext\&pid=S185245082011000200004\&Ing=es\&nrm=iso (Consultado el 11-04-2012).

KERBO, HAROLD (2004) Estratificación y desigualdad. El conflicto de clases en perspectiva histórica, comparada y global, Mc Grawill/ Interamericana de España. España.

KESSLER, GABRIEL Y VICENTE ESPINOZA (2007) "Movilidad social y trayectorias ocupacionales en Buenos Aires. Continuidades, rupturas y paradojas", en FRANCO, RAUL, ARTURO LEÓN Y RAÚL ATRIA (Coordinadores) (2007) Estratificación y movilidad social en América Latina. Transformaciones estructurales de un cuarto de siglo. LOM-CEPAL-GTZ. Santiago de Chile.

MACHUCA, RAÚL (2008) "Deuda, produccion y exportacoin de bienes primarios ¿las raíces de la pobreza y desigualdad latinoamericana?", Presentado en el seminario "producción de Pobreza en América Latina y El Caribe", Lima, Perú, 15 al 17 de Octubre de 2008, CLACSO CROP - DESCO.

MARGULIS, MARIO (1999) "La racialización de las relaciones de clase", en MARGULIS, MARIO y MARCELO URRESTI (compiladores) (1999) La segregación negada. Cultura y discriminación social. Biblos. Buenos Aires

MARGULIS, MARIO (2002) "La ciudad y sus signos" en Estudios Sociológicos XX, No 60, Buenos Aires. pp. 515-536.

MARGULIS, MARIO (2006) "Ideología, fetichismo de la mercancía y reificación", en Revista Sociedad, No 25, Facultad de Ciencias Sociales, UBA, Buenos Aires. pp. 49-84.

MARGULIS, MARIO (2007) "Carmen va al trabajo" en MARGULIS, MARIO; MARCELO URRESTI Y HUGO LEWIN (2007) Familia, hábitat y sexualidad en Buenos Aires. Ed. Biblos. Buenos Aires.

MARGULIS, MARIO Y CARLOS BELVEDERE (1999) "La racialización de las relaciones de clase: Genealogía de la discriminación”, MARGULIS, MARIO y MARCELO URRESTI 
(compiladores) (1999) La segregación negada. Cultura y discriminación social. Biblos. Buenos Aires.

MARIÁTEGUI, JOSÉ CARLOS (1995) 1928 Siete ensayos de interpretación de la realidad peruana. Biblioteca Amauta. Lima.

MARINI, RUY MAURO (1991) Dialéctica de la dependencia. Edit. Era. México.

MARSHALL, T. H. (1949), "Ciudadanía y clase social", Conferencia dictada en Cambridge. Version en español en THOMAS HUMPHREY MARSHALL, MA. TERESA CASADO AND FRANCISCO JAVIER NOYA MIRANDA Reis: Revista Española de Investigaciones Sociológicas, No 79 (Jul. - Sep., 1997), pp. 297-344.

MORENO FRAGINALS, MANUEL (1977) "Aportes culturales y deculturación" en UNESCO: África en América Latina. Siglo XXI Editores. México

NOGUEIRA, ORACY (2008) "Color de Piel y Clase Social" en Vibrant, Volumen 5. Numero

1. Fuente: www.vibrant.org.br/downloads/v5n1_oracy_es.pdf (Consultado el 23-03-2011).

PREISWERK, ROY Y DOMINIQUE PERROT (1979) "La legitimación unilateral de la acción de Occidente" en Etnocentrismo e Historia. Nueva Imagen. México.

QUIJANO, ANÍBAL (2000a) "Colonialidad del poder y clasificación social" en Journal of world-systems research, vi, 2, summer/fall 2000. pp.342-386.

QUIJANO, ANÍBAL (2000b) "El fantasma del desarrollo en América Latina" en Revista venezolana de Economía y Ciencias Sociales, Vol. 6 № 2 (mayo-agosto), pp. 73-90.

QUIJANO, ANÍBAL (2003) "Colonialidad del poder, eurocentrismo y América Latina" en LADER, EDGARDO (compilador) La colonialidad del saber: eurocentrismo y ciencias sociales. Perspectivas Latinoamericanas. UNESCO - CLACSO. Buenos Aires.

QUIJANO, ANÍBAL (2005) "Don Quijote y los molinos de viento en América Latina" en Libros y Artes, Revista de Cultura de la Biblioteca Nacional del Perú, No. 10, Abril 2005. Lima, Perú. pp. 14-16.

QUINTERO, PABLO (2010) "Notas sobre la teoría de la colonialidad del poder y la estructuracion de la sociedad en América Latina" en en Papeles de Trabajo, Centro de Estudios Interdisciplinarios, Etnolingüísticas, Antropológicos y Socioculturales, Rosario, $\mathrm{N}^{\circ} 19$, Junio 2010. Disponible en http://rephip.unr.edu.ar/bitstream/handle/2133/1586/n19a01.pdf? sequence=1(Consultado el 10-04-2012).

REID ANDREWS, GEORGE (1989) Los afro argentinos de Buenos Aires. Ediciones la Flor. Buenos Aires.

SAÍD, EDWARD, (2005) "Cultura, identidad e historia" en SCHRÖDER, GERHART Y HELGA BRUNINGER (comps.) Teorías de la cultura. Un mapa de la cuestión. FCE. Buenos Aires.

SALVIA AGUSTÍN Y EDUARDO CHÁVEZ MOLINA (coords.) (2007), Sombras de una marginalidad fragmentada. Aproximaciones a la metamorfosis de los sectores populares de la Argentina. Miño y Dávila. Buenos Aires

SMITH BELOTE, LINDA Y JIM BELOTE (2000) "Fuga desde abajo: Cambios individuales de identidad étnica en el Sur de Ecuador" en Guerrero, Andrés (compilador) Etnicidades, ILDIS FLACSO Fundacion Friedrich Ebert, Ecuador.

STAVENHAGEN, RODOLFO (1965). "Siete tesis equivocadas sobre América Latina", en América Latina, ensayos de interpretación sociológico-politica. Editorial Universitaria. Santiago de Chile. pp. 82-93.

STAVENHAGEN, RODOLFO (1994) "Racismo y xenofobia en tiempo de globalización" en Estudios Sociollógicos, XII: 34, págs - 16, El Colegio de México.

TODOROV, TZVETAN (1987) "Conquistar", en La Conquista de América: la cuestión del Otro. Siglo XXI. México.

TODOROV, TZVETAN (1991) Nosotros y los otros. Reflexiones sobre la diversidad humana. Siglo XXI Editores. México 
Papeles de Trabajo No 23 -Julio 2012 - ISSN 1852-4508

Centro de Estudios Interdisciplinarios en Etnolingüistica y Antropología Socio-Cultural

WALLERSTEIN, IMMANUEL (1974) The modern world-system. Capitalist agricultur and the origins of the European world-economy in the sixteenth century. Academic Press. New York. 